Clemson University

TigerPrints

2018

Supporting elementary teachers' enactment of nature of science instruction: a randomized controlled trial

Jennifer L. Maeng

Randy L. Bell

Tyler St. Clair

Amanda L. Gonczi

Brooke A. Whitworth

Follow this and additional works at: https://tigerprints.clemson.edu/teach_learn_pub

Part of the Science and Mathematics Education Commons 


\section{IJ International Journal of Science Education}

\section{Supporting elementary teachers' enactment of nature of science instruction: a randomized controlled trial}

Jennifer L. Maeng, Randy L. Bell, Tyler St. Clair, Amanda L. Gonczi \& Brooke A. Whitworth

To cite this article: Jennifer L. Maeng, Randy L. Bell, Tyler St. Clair, Amanda L. Gonczi \& Brooke A. Whitworth (2018): Supporting elementary teachers' enactment of nature of science instruction: a randomized controlled trial, International Journal of Science Education, DOI: 10.1080/09500693.2018.1528643

To link to this article: https://doi.org/10.1080/09500693.2018.1528643

曲 Published online: 07 Oct 2018.

Submit your article to this journal $₫$

View Crossmark data $\asymp$ 


\title{
Supporting elementary teachers' enactment of nature of science instruction: a randomized controlled trial
}

\author{
Jennifer L. Maeng (D) ${ }^{a}$, Randy L. Bell ${ }^{b}$, Tyler St. Clair $\mathbb{B}^{c}$, Amanda L. Gonczi ${ }^{d}$ and \\ Brooke A. Whitworth (1D) \\ ${ }^{a}$ Curry School of Education, University of Virginia, Charlottesville, VA, USA; ${ }^{b}$ College of Education, Oregon \\ State University, Corvallis, OR, USA; 'School of Education and Professional Studies, SUNY Potsdam, Potsdam, \\ NY, USA; ${ }^{\mathrm{d} G r e a t}$ Lakes Research Center, Michigan Technological University, Houghton, MI, USA; 'Department \\ of Teacher Education, University of Mississippi, Oxford, MS, USA
}

\begin{abstract}
This embedded mixed method study used a randomised controlled trial design to examine two cohorts of upper (grades 4-6) elementary teachers' classroom implementation of nature of science (NOS) instruction following their participation in a statewide professional development (PD). The treatment group ( $n$ $=145$ ) was compared to a control group $(n=90)$, which received no PD. The PD included a summer institute that situated explicit NOS instruction within the context of problem-based learning (PBL). Data sources included videotaped classroom observations across four time points and teacher-generated descriptions of lessons preceding and following the observed lesson including learning objectives. Data were analysed with descriptive and inferential statistics and analysed qualitatively for trends in participants' explicit NOS instruction. Results indicated the majority of treatment teachers $(n=97 ; 66.9 \%)$ accurately taught explicit NOS during the academic year following the summer institute compared to control teachers $(n=2 ; 2.2 \%)$. Participants most often taught about the empirical (69\%) and social (63\%) aspects of science. Participants' strategies for integrating NOS varied in temporal placement within the lesson, connectedness to lesson activities, and extent of student-centeredness. These results demonstrate that situated PD that contextualises explicit NOS instruction within PBL facilitated teachers' explicit NOS instruction compared to teachers who did not receive such instruction.
\end{abstract}

\section{ARTICLE HISTORY}

Received 7 November 2017

Accepted 23 September 2018

\section{KEYWORDS}

Nature of science; randomised controlled trial; elementary professional development

Science educators agree that understanding characteristics of scientific knowledge and how scientific knowledge is developed are key components of scientific literacy (e.g. Driver, Leach, Millar, \& Scott, 1996; Lederman \& Lederman, 2014; McComas, Clough, \& Almazroa, 1998; Osborne, Collins, Ratcliffe, Millar, \& Duschl, 2003). Characteristics of scientific knowledge, including the values and assumptions that accompany its development, comprise the nature of science (NOS) construct. It is important that students at all grade levels have opportunities to learn about these fundamental ideas in order to make 
more informed choices and have a deeper understanding about a range of socio-scientific issues (American Association for the Advancement of Science [AAAS], 1993; NGSS Lead States, 2013). The present study investigated the efficacy of professional development (PD) that contextualised NOS instruction within problem-based learning (PBL) in supporting elementary teachers' explicit NOS instruction through classroom observations and a randomised controlled trial (RCT) design.

While consensus exists among the science education community on the importance of teaching NOS (e.g. Driver et al., 1996; Lederman \& Lederman, 2014; McComas et al., 1998; Osborne et al., 2003), some disagreement exists around the concepts that comprise NOS (Bell, Mulvey, \& Maeng, 2016). However, science educators generally agree on several NOS concepts that are appropriate for K-12 science instruction (Bell et al., 2016; Lederman, 2007; Lederman \& Lederman, 2014; McComas et al., 1998; NGSS Lead States, 2013; Osborne et al., 2003). Agreed-upon concepts include: science addresses questions about the natural world; scientific knowledge is empirically-based; science is revisionary; scientific investigations use a variety of methods; creativity and imagination are importance to science; theories and laws are different types of scientific knowledge, but both are supported by evidence and can change; science is subjective; and science is socially and culturally embedded. These concepts provide a general framework for understanding science as a way of knowing for K-12 students (Lederman \& Lederman, 2014). It is therefore important that that teachers understand these concepts so that they can help their students develop appropriate NOS understandings.

\section{Elementary teachers' NOS understandings}

Decades of research suggest only a small number of teachers possess accurate NOS understandings without targeted NOS instruction either in preservice teacher preparation programmes or through PD (Lederman \& Lederman, 2014). For example, investigations using pre-test/post-test designs have repeatedly demonstrated that preservice and in-service elementary teachers hold inaccurate or inadequate understandings of NOS concepts at pre-test (e.g. Abd-El-Khalick \& Akerson, 2009; Akerson \& Hanuscin, 2007; Akerson, Abd-El-Khalick, \& Lederman, 2000). Despite this challenge, several studies suggest that PD has the potential to support the development of teachers' accurate NOS understandings (e.g. Akerson \& Hanuscin, 2007; Akerson, Cullen, \& Hanson, 2009; Donnelly \& Argyle, 2011; Maeng, Bell, St. Clair, Whitworth, \& Gonczi, 2016; Mulvey, Chiu, Ghosh, \& Bell, 2016).

The positive results of these studies suggest that a key feature in developing teachers' accurate NOS understandings is explicit instruction supported with reflective discussions (e.g. Akerson \& Hanuscin, 2007; Lederman \& Lederman, 2014; Maeng et al., 2016; Scharmann, Smith, James, \& Jensen, 2005; Schwartz, Lederman, \& Crawford, 2004). Explicit reflective NOS instruction is characterised by intentionally focusing learners' attention on NOS concepts 'through instruction, discussion, and questioning ... in the context of activities and investigations ...' (Schwartz \& Lederman, 2002, p. 207).

Indeed, results of a RCT reported that elementary teachers who participated in PD that included explicit NOS instruction contextualised within a problem-based learning (PBL) context, significantly improved their NOS understandings after controlling for pre-PD NOS understandings compared to a control group who did not participate in 
the PD (Maeng et al., 2016). However, that study did not report whether or not the teachers' understandings were translated into explicit NOS instruction in their own classrooms. The present study utilised the same PD context as the Maeng et al. (2016) investigation but extends the findings of that study to investigate teachers' NOS instruction.

\section{Elementary teachers' NOS instruction}

Developing teachers' accurate NOS understandings is not enough to ensure that they are actually teaching these concepts to their students (Lederman \& Lederman, 2014). Research indicates that even when teachers demonstrate accurate understandings of NOS few go on to address NOS concepts in their classroom instruction (e.g. Abd-El-Khalick, Bell, \& Lederman, 1998; Lederman, 1999). For example, Abd-El-Khalick et al. (1998) found that while the 14 preservice science teachers in their study held an adequate understanding of several NOS concepts (e.g. empirical basis, tentativeness, role of subjectivity and creativity) and perceived NOS to be important to teach students, only 3 actually planned to implement explicit NOS instruction.

Given this challenge, recent investigations have sought to understand how best to support teachers in implementing NOS in instruction after developing their accurate NOS understandings. In a single case study, Akerson and Abd-El-Khalick (2003) reported on the substantial modelling and personal support necessary for a 4 th grade teacher with informed NOS understandings and the intention to teach NOS to teach NOS to her students. Similarly, Akerson and Hanuscin (2007) found that monthly professional development and individual coaching was sufficient to promote three elementary teachers' explicit NOS instruction in a 3-year PD programme. Thus, several elements of PD (e.g. modelling explicit, reflective NOS, coaching) have evidentiary support in facilitating teachers' explicit NOS instruction.

While research has established several contexts (e.g. history of science, socio-scientific issues, scientific inquiry, content) that appear promising in developing teachers' accurate NOS understandings (e.g. Bell, Matkins, \& Gansneder, 2011; Sadler, Burgin, McKinney, \& Ponjuan, 2010; Scharmann et al., 2005), less research investigates the contexts that support teachers' NOS instruction (e.g. Bell et al., 2016; Bell, Mulvey, \& Maeng, 2012; Herman, Clough, \& Olson, 2013). Results of a study that investigated beginning secondary teachers' NOS instruction after completing a science teacher preparation programme that incorporated NOS within a science content context in several courses indicated that $70 \%$ of the secondary teachers had high or medium NOS implementation scores (Herman et al., 2013). Despite the intensive programme, these teachers were observed having more difficulty integrating NOS instruction when they were teaching science content rather than when teaching inquiry. Similarly, Bell et al. (2012) investigated outcomes of a secondary teacher preparation programme that contextualised NOS instruction using a 'process skills-based' approach. They found that all of the teachers integrated NOS into their science instruction and $70 \%$ of the teachers innovated to teach NOS using the process skills-based approach. However, none of the teachers taught about the social and cultural embeddedness of science. A qualitative case study investigated four elementary special education teachers' explicit NOS practices following $\mathrm{PD}$ that contextualised NOS instruction along a continuum from less to more 
contextualised in science content and inquiry (Mulvey et al., 2016). Results indicated that following the 2-week PD, all 4 teachers included several NOS concepts in their instruction. Despite the varied sample demographics and methodological approaches, the results of these studies illuminate several potential contexts that may support teachers' classroom NOS instruction.

Problem-based Learning as a Context for NOS Instruction. In light of the synergy between the key NOS concepts and PBL, Moutinho, Torres, Fernandes, and Vasconcelos (2015) proposed PBL as a potential context that may support teachers' NOS instruction. PBL is a student-centered approach that supports real-world application of science knowledge to solve a problem (Chin \& Chia, 2004; Crawford, 2014). In PBL, students work to solve an authentic, meaningful problem with the potential for multiple solutions, collaborate with one another, and engage in investigations (Hmelo-Silver, 2004). Students are presented with a scenario, take on the role of scientists that would be working on the problem, and may be given a title such as 'Junior Oceanographer,' 'Apprentice Rollercoaster Engineer' or 'Consultant to the EPA' that serves to introduce students to possible STEM career paths they could pursue in the future. Students typically work in small groups to conduct a number of investigations (i.e. engage in inquiry and employ scientific practices) and synthesise their investigative findings to help them solve the problem. Because PBL problems have multiple solutions, student groups often present (e.g. verbal presentation, video, model) their solution and provide evidence from their investigations to support their proposed solution.

Given this pedagogical structure, PBL has the potential to provide context for explicit NOS instruction because it supports students working collaboratively and creatively to solve a problem and engaging in investigations to learn science content. In their qualitative study of 17 Portuguese preservice science teachers, Moutinho and colleagues (2015) used interviews to probe the NOS concepts preservice teachers perceived 'can be developed through PBL' (p. 1873). The results indicated PBL can help preservice teachers explain the tentative, or revisionary, NOS, that the development of scientific knowledge is socially and culturally embedded, and that creativity and imagination are important to the development of scientific knowledge. Further, the preservice teachers thought explicitly embedding NOS into a PBL unit may support students' understanding of how their investigations are similar to the work of practicing scientists and the complexity of the scientific endeavour (Moutinho et al., 2015). However, this study did not investigate implementing PBL as a context for NOS instruction. The PD that served as the context of the present investigation emphasised a subset of NOS concepts that are agreed upon by the science education community and are well-aligned with PBL pedagogy (Figure 1).

- Science addresses questions about the natural/material world.

- Scientific knowledge is empirically-based.

- Science is revisionary.

- Scientists use a variety of methods.

- Creativity and imagination are important to science.

- Science is socially and culturally embedded.

Figure 1. NOS understandings aligned with PBL pedagogy and emphasised during PD. 


\section{Characteristics of effective PD}

PD is effective when it is designed to acknowledge teachers' current understandings and instruction, is context and content-specific, fosters collaboration, and provides teachers with opportunities for practice, active participation, reflection, and feedback (e.g. Desimone, 2009; Loucks-Horsley, Stiles, Mundry, Love, \& Hewson, 2010; Supovitz \& Turner, 2000). In order to support changes in teachers' understandings and practices, PD should also be sustained and ongoing (e.g. Johnson, Kahle, \& Fargo, 2007; Supovitz \& Turner, 2000). Expert and ongoing coaching may also facilitate teachers' integration of new teaching strategies (Loucks-Horsley et al., 2010). Situated learning theory suggests that because a person's understanding of a concept is constantly under construction, knowledge must be learned in the context within which it will be used, and that interactions among individuals support the development of knowledge (Orgill, 2007). Specifically, the PD that served as the context for the present investigation used a situated learning approach to integrate these effective PD components to support elementary science teachers' inclusion of explicit NOS instruction in their classrooms. As described in the methods section that follows, the PD was sustained and ongoing, elementary science-specific, fostered collaboration, and provided opportunities for feedback, reflection, and practice.

\section{Purpose}

The efficacy of learning NOS has been studied in a variety of populations (e.g. elementary and secondary students, preservice and in-service elementary and secondary teachers) and contexts (e.g. science content, inquiry, historical cases). However, despite the synergy between NOS concepts and PBL pedagogy, no research investigates how explicit NOS instruction within the context of PBL may support the transfer of teachers' NOS understandings into classroom instruction.

Of studies that explore in-service elementary teachers' NOS understandings following PD, few examine teachers' classroom NOS practices following PD (e.g. Akerson, Hanson, \& Cullen, 2007; Morrison, Raab, \& Ingram, 2008). Of the few that do, most rely on teachers' self-reports to assess NOS instruction (e.g. Donnelly \& Argyle, 2011). Many of these case studies also focus on specific lessons and how teachers implement NOS instruction as examples rather than exploring patterns in teachers' NOS instruction. While much can be learned from these case studies, we must also look more broadly at how teachers incorporate NOS into their instruction to determine how to better support teachers' NOS instruction. This includes investigating the NOS concepts teachers choose to incorporate/not incorporate and the frequency with which they incorporate these concepts.

The present study seeks to extend the work of these prior investigations by utilising a randomised controlled trial (RCT) design to investigate the efficacy of PD informed by situated learning theory and that contextualised explicit NOS instruction within PBL to support teacher's explicit NOS instruction. The present study also builds on a prior RCT that demonstrated that participation in the PD resulted in significantly improved NOS understandings for elementary teachers (Maeng et al., 2016). Specifically, in the present study, we examined participants' classroom implementation of NOS following PD participation. The following research questions guided this investigation. 
(1) How did the frequency of PD participants' explicit NOS instruction compare to teachers in the control group?

(2) How did PD participants' integrate explicit NOS instruction into their science instruction following the PD?

\section{Methods}

A RCT evaluated PD participants' NOS instruction compared to a control group who did not participate in the PD. An embedded mixed methods design (Creswell \& Plano Clark, 2011) in which quantitative data analysis (e.g. frequency of NOS instruction) occurred simultaneously with qualitative data analysis (e.g. NOS concepts) was used to understand the frequency with which and how elementary teachers incorporated NOS into science instruction.

\section{Participants}

Teachers voluntarily signed up to participate in the PD with the knowledge they would be randomly assigned to either the treatment or control condition. Voluntary (rather than required participation) in the PD ensured teachers in both the treatment and control conditions had comparable motivations to participate (Kennedy, 2016). Random assignment occurred at the school level; all teachers from the same school were assigned the same condition to prevent treatment diffusion. To ensure even teachers randomised into the control condition had the opportunity to experience the $\mathrm{PD}$, they were invited to attend the PD the following year. Participants randomised into the treatment group comprised two cohorts totalling 145 elementary teachers of whom 90.3\% $(n=131)$ had degrees in education and whose science teaching experience ranged from 0 to 31 years $(M=7.2$ years, $\mathrm{SD}=6.7)$. Participants randomised into the control group were 90 elementary teachers of whom $91.1 \%(n=82)$ reported degrees in education and had science teaching experience ranging from 0 to 25 years $(M=6.5$, $\mathrm{SD}=5.9$ ). Demographic data (Table 1) were self-report and pseudonyms are used throughout to protect participant identity.

Treatment participants were from 60 different elementary schools that varied in the percent of English Language Learners $(M=8.9 \%, \mathrm{SD}=12.5)$, percent of students eligible for free and reduced priced lunch $(M=45.7 \%, \mathrm{SD}=27.8)$, and the percent of White students $(M=46.1 \%, \mathrm{SD}=27.4)$. Control teachers were from 39 different elementary schools that varied in the percent of English Language Learners $(M=9.7 \%, \mathrm{SD}=14.8)$, percent of students eligible for free and reduced priced lunch $(M=44.1 \%, \mathrm{SD}=20.0)$, and the percent of White students $(M=61.2 \%, \mathrm{SD}=27.5)$.

Table 1. Participant demographic data.

\begin{tabular}{|c|c|c|c|c|c|c|c|c|}
\hline \multirow{2}{*}{ Condition } & \multicolumn{2}{|c|}{ Gender } & \multicolumn{5}{|c|}{ Race/Ethnicity } & \multirow{2}{*}{$\begin{array}{c}\text { Deg. Sci. } \\
\text { Yes }\end{array}$} \\
\hline & Female & Male & White & Black & Hispanic/Latinx & Asian & Mixed & \\
\hline $\begin{array}{l}\text { Treatment } \\
\qquad(n=145)\end{array}$ & $\begin{array}{c}128 \\
(88.2 \%)\end{array}$ & $\begin{array}{c}13 \\
(9.0 \%)\end{array}$ & $\begin{array}{c}110 \\
(75.9 \%)\end{array}$ & $\begin{array}{c}25 \\
(17.2 \%)\end{array}$ & $\begin{array}{c}2 \\
(1.4 \%)\end{array}$ & $\begin{array}{c}2 \\
(1.4 \%)\end{array}$ & $\begin{array}{c}2 \\
(1.4 \%)\end{array}$ & $\begin{array}{c}18 \\
(12.4 \%)\end{array}$ \\
\hline $\begin{array}{l}\text { Control } \\
(n=90)\end{array}$ & $\begin{array}{c}74 \\
(82.2 \%)\end{array}$ & $\begin{array}{c}16 \\
(11.0 \%)\end{array}$ & $\begin{array}{c}75 \\
(83.3 \%)\end{array}$ & $\begin{array}{c}9 \\
(10 \%)\end{array}$ & $\begin{array}{c}1 \\
(1.1 \%)\end{array}$ & $\begin{array}{c}1 \\
(1.1 \%)\end{array}$ & $\begin{array}{c}0 \\
(0 \%)\end{array}$ & $\begin{array}{c}8 \\
(8.9 \%)\end{array}$ \\
\hline
\end{tabular}

Note: Not all teachers reported demographic information. 


\section{Intervention}

Treatment participants attended a PD programme that included a 4-week summer institute (152 contact hours) with sustained follow-up and coaching throughout the academic year at one of four universities in a mid-Atlantic state. Combining participants across sites and cohorts was warranted as programme evaluation documented that the summer institute was planned and implemented consistently and with fidelity across sites and cohorts (Bell, Konold, Maeng, \& Heinecke, 2014). Teams of university science educators, scientists, engineers, and science and mathematics specialists co-planned and facilitated the summer institute.

During the first week of the summer institute the PD supported participants' understandings and enactment of NOS instruction within the context of PBL, as well as other reforms-based instructional approaches and topics (e.g. technology integration, engineering design, inquiry instruction, literacy integration, math integration). On the first two days of the PD, participants acted as students in several lessons embedded within an abbreviated model PBL unit. To begin, teachers were asked to solve an overarching problem and were provide with a scenario and given a role aligned with the authentic roles of scientists or engineers working on similar problems, such as Junior Environmental Engineer, Science Museum Consultant, and Junior Wildlife Advisory Committee Member. Then, they brainstormed the questions they would need to answer to address the overarching PBL question. Teachers then engaged in several lessons that modelled how PBL could be used as a context for scientific inquiry, explicit NOS instruction, and engineering design). Participants debriefed the experience by discussing the components of the lessons and overarching structure that supported their learning as a student. They were then introduced to key components of PBL (e.g. overarching problem question, scenario, student role, culminating activity, question map) and used the modelled PBL unit from the first two days as a common experience from which to discuss these components of PBL. Finally, they learned a formal definition of PBL: 'Students solving a meaningful problem with multiple solutions over time, as a scientist would in a real world context. The problem and context must be meaningful to students.'

During week 1, participants engaged in several activities that focused on the NOS concepts in Figure 1. These included a NOS card sort that contained accurate and inaccurate statements about NOS and was designed to elicit participants' initial ideas and potential alternative conceptions about NOS. This activity served as a pre-assessment for PD facilitators and was revisited several times throughout the PD as a formative assessment of changes in participants' understandings.

Participants also took part in several modelled lessons that embedded explicit and reflective NOS instruction within a PBL unit. For example, facilitators modelled how to integrate aspects of NOS into a lesson embedded within a PBL unit on marine systems. The overarching problem question for the unit was 'Where and how can a self-sustaining research facility be built with the least impact on the environment that can support scientists as they conduct research on marine systems?' In one activity, participants were provided an unknown sample (a crinoid stem fossil fragment) from the ocean floor. They made observations of their sample and inferred, based on their observations and prior knowledge, what the sample was. Next, they used a variety of tools (e.g. hand lens) to further explore and observe the sample and refine their inferences about the object. 
Participants then discussed the implications of finding such an artifact for their work at that particular ocean site. Finally, facilitators debriefed the activity through questions that elicited the NOS concepts embedded within the lesson from participants. Specifically, these included that scientific knowledge is based on empirical evidence, scientific knowledge can change with new evidence or reinterpretation of existing evidence, and scientists use many methods to develop knowledge.

Following this initial instruction and with facilitator support, participants then coplanned a PBL unit that integrated NOS concepts and other reform-based instructional strategies. They taught this unit during a two-week summer camp (weeks two and three of the PD) for high-needs 4th-6th grade students. Each day after teaching, the participants debriefed the lessons and activities. They discussed whether NOS was effectively taught, with particular attention to explicit instruction and how they might more effectively engage students in reflective discussions about NOS.

The fourth week of the PD participants worked with other teachers from their school as well as their classroom coach and facilitators to plan a PBL unit that integrated NOS concepts to be implemented in their own classrooms during the academic year. Thus, NOS was integrated in substantive ways throughout the four weeks of the summer institute.

During the academic year, participants participated in 14 hours of follow-up PD. This follow up included attending the state science teacher professional development institute, reflecting and receiving feedback on classroom PBL unit implementation, and revisiting and elaborating upon topics from the summer including NOS, simulations to support inquiry, and formative assessment strategies. In addition, coaches, who were experienced teachers, worked with participants an additional 22 hours across the academic year to coplan, co-teach, observe, promote reflection, and provide feedback on teachers' science instruction. The coaching predominately took place when the teachers were implementing the PBL unit they designed during the summer, which varied by teacher depending on their curriculum, PBL unit topic, and pacing guide. See Mannarino, Logerwell, Reid, and Edmondson (2012) for a complete description of the PD.

\section{Data collection and analysis}

Videotaped classroom observations were conducted four times at regular intervals throughout the academic year, within the same three-week interval for all treatment and control teachers. Observation forms documented lesson objectives, descriptions of the three lessons occurred prior to the observed lesson and the three lessons that followed the videotaped lesson. Observers visited each teacher's classroom once during each observation period to videotape their science instruction and collected contextual information on observation forms regarding the observed lesson per a validated observation protocol (Bell, Konold, Maeng, \& Heinecke, 2014).

We used several strategies to mitigate the potential that teachers would adjust their instruction to what they perceived observers would find important. First, teachers did not know when observations would occur until just prior to the observation windows. Second, we reviewed observation forms to ensure the progression between lessons that occurred prior to and following the observed lessons flowed coherently. Finally, the fact that the PD addressed several topics and pedagogies including PBL, inquiry instruction, 
NOS, engineering design, and technology integration, mitigated the potential threat that participants might view these observations as solely assessments of their NOS instruction and alter their instruction accordingly.

These classroom observation data (i.e. observation forms and videos) were coded for the presence (1) or absence (0) of explicit NOS instruction. Explicit NOS instruction was operationally defined as instruction that models, discusses, and distinguishes between the 'how' and 'why' of doing science (Gess-Newsome, 2002) and that addressed one or more of the NOS concepts in Figure 1. For those observation periods in which explicit NOS instruction was noted, the specific NOS concepts taught were also coded (e.g. empirical, understandable). In instances where no explicit NOS instruction was identified on the observation form or videotaped observation, the participant's NOS instruction for that observation period was coded as 0 . All of the observation data initially coded as containing explicit NOS were then coded by a second rater for explicit NOS instruction and specific NOS concepts. Instances in which the second rater disagreed with the explicit NOS code for the observation period were recoded as 0 . Interrater agreement for this initial analysis was $89 \%$. Instances in which the second rater disagreed with the specific NOS concepts taught were resolved through discussion until consensus was reached. This process allowed us to systematically determine both the frequency of NOS instruction and the specific NOS concepts taught by participants.

Chi-square tests for independence with Yates Continuity Correction evaluated whether the frequency of explicit NOS instruction differed between treatment and control participants. The two variables were group (treatment or control) and incorporation of explicit NOS (yes or no). The Phi coefficient $\left(r_{\varphi}\right)$, which ranges from 0 to 1 , was used as a measure of effect size with the two by two contingency tables.

Finally, to characterise how teachers integrated explicit NOS instruction into their lessons, the videotaped classroom observations that included explicit NOS instruction were analysed qualitatively. In this inductive approach, memos were written for each lesson in which NOS instruction was observed (as per Miles \& Huberman, 1994). Next, common themes in teachers' explicit NOS instruction were developed from the memos and informed by the literature (e.g. Clough, 2006; Schwartz \& Lederman, 2002). These themes were reviewed and agreed upon by the entire research team. Themes included: the extent to which the NOS concepts were explicitly connected with lesson activities/ content (not connected/connected), the extent NOS reflection was teacher-driven or student-centered, the temporal placement of explicit NOS instruction during the lesson (e.g. introduction, body, closure), and the potential for a lesson to reinforce alternative conceptions about NOS. Connected explicit NOS instruction was characterised by a strong association with the science content and activities addressed in the lesson whereas not connected explicit NOS instruction was characterised by a lack of connection to the science content or activities during the lesson. Student-driven NOS instruction was characterised by opportunities for student reflection or for students to make their own associations between the science content/activities and the NOS concepts addressed, while teacher-driven explicit NOS instruction was characterised by the teacher explicitly identifying the NOS concepts addressed in the lesson without the opportunity for students to reflect or make associations. These themes and observation data to support them are elaborated in the results section below. 


\section{Results}

The present study utilised a RCT design to investigate the efficacy of PD informed by situated learning theory and that contextualised NOS instruction within PBL. Specifically, we examined the frequency of explicit NOS instruction following PD as compared to a control group and the characteristics of participants' explicit NOS instruction.

\section{Frequency of integration}

Analysis of classroom observations and observation forms indicated two thirds of participants explicitly taught NOS during one or more of the observation windows following the PD (66.9\%). Of the participants who explicitly taught NOS, 55\% taught NOS in at least two observation windows and $9 \%$ explicitly taught NOS in all four observation windows. In contrast, only 2 (2.2\%) of the control participants were observed explicitly teaching NOS concepts at any point during the year. This represents a statistically significant difference between treatment and control participants' NOS integration, $\chi^{2}(1)=92.6$, $p<.001,=r_{\varphi}=.637$. The large effect size $\left(r_{\varphi}>.5\right)$ combined with a statistically significant association, represents a practically and statistically meaningful effect (Fan, 2001).

Looking more closely at the subset of teachers in the treatment group who actually taught NOS, the role evidence plays in the development of scientific knowledge and the idea that science is a social endeavour were the most frequently observed explicit NOS concepts taught (71\% and 65\% respectively; Table 2). Approximately $40 \%$ of teachers explicitly highlighted the natural world is understandable and that creativity and imagination are important to science. About a quarter $(27.8 \%)$ of teachers addressed the notion that scientists use multiple methods to develop knowledge. However, few teachers discussed the idea that scientific knowledge is both tentative and durable (13\%).

Of the two control participants who explicitly taught NOS, one addressed the idea that science is understandable. The other introduced students to the idea that scientific knowledge is subject to change with new evidence in a lesson that used a historical approach to teach how scientists' perspective on the solar system changed from geocentric to heliocentric.

\section{Strategies for explicit NOS instruction}

The data revealed a several strategies participants utilised to incorporate explicit NOS instruction into their science instruction. These strategies included the extent to which the targeted NOS concepts were explicitly connected with lesson activities (not connected

Table 2. Concepts explicitly taught by treatment participants $(n=97)$.

\begin{tabular}{lc}
\hline NOS Understandings Explicitly Taught & Number of Teachers \\
\hline Scientific knowledge is empirically-based. & $69(71.1 \%)$ \\
Science is socially and culturally-embedded. & $63(64.9 \%)$ \\
Science addresses questions about the natural/material world. & $42(43.3 \%)$ \\
Creativity and imagination are important to science. & $39(40.2 \%)$ \\
Scientists use a variety of methods. & $27(27.8 \%)$ \\
Science is revisionary. & $13(13.4 \%)$ \\
\hline
\end{tabular}

Note: Percentages will not add up to 100 because a participant could teach more than one NOS concept across the year. 
versus connected) and whether NOS reflection was teacher-driven or student-centered. There was also some variation in the temporal placement of NOS instruction within the lesson (i.e. introduction, body, closure). Below, we describe and exemplify the combination of strategies observed to support explicit NOS instruction.

Not connected, teacher-driven. This type of explicit NOS instruction was characterised by a general review of all the NOS concepts taught in the PD either to introduce or close a lesson. In these lessons, the teacher verbally told students one or more NOS concepts without eliciting student feedback. This NOS instruction was not strongly associated with the science content and did not promote student reflection.

Connected, teacher-driven. In connected, teacher-driven NOS instruction, the teacher explicitly identified NOS concepts within the context of describing science phenomena but did not promote reflection by students about the targeted concepts. Rather, in these lessons, teachers were observed telling students at the beginning or end of the lesson how they would be acting like scientists or how they acted like scientists. For example, in an activity in which students in a 5th grade class worked to answer the question, 'How do scientists test the characteristics of matter?' students explored the concept of density by predicting then observing whether a variety of objects sink or float. After the activity, Lisa directed students to move into a circle on the floor.

\section{Example 1}

The students spent about 10 minutes discussing what they knew and did not know before the activity, what observations surprised them, what predictions were not supported by their data, and how the ideas would be important for recreational sports. In addition, some students asked questions about what they still did not understand and other students responded. Lisa concluded the discussion and lesson with the statement, "one of the principles of science is that the natural world is understandable and you have been answering a lot of your own questions through the experiment you did. I like how you as scientists were social and shared ideas." (Lisa, Observation 1).

In this example, Lisa identified the targeted NOS concepts for students and how they connected with the activities, rather than having the students reflect upon how they acted like a scientist. This represented explicit NOS instruction, but did not provide students an opportunity to reflect on the NOS concepts themselves or identify how they connected to the lesson.

Connected, student-centered. Lessons characterised by connected, student-centered instruction involved teachers asking students to tell them how the activity related to NOS concepts during lesson closures. This represented a connected and student-centered approach to explicit NOS instruction. In these lessons, the brief discussions often began with teachers asking students the question, 'How did you act like a scientist today?' as exemplified in the following example in Tory's 5th grade class. Tory's stated objectives for the observed lesson were that students would understand the parts of a plant through plant dissection and the difference between vascular and non-vascular plants.

Example 2

Tory began the lesson prompting students to think back to a previous discussion about how living things are organized into kingdoms. Autumn shared that, "At first it was just two groups: plants and animals. Then, some of them didn't fit in so they made the 5 kingdoms." Tory asked, "What does that say about science as a whole?" and Robert responded that, 
"Science is always changing." Tory followed this up with the question, "Does it just change because willy-nilly?" Kiera replied, "No, because they based it off of new evidence." Tory affirmed this response, "Absolutely."

Tory then told students they would be exploring the plant kingdom today. They shared what they know about plants then reviewed the major plant parts and dissected a flower. The lesson continued with a whole class discussion in which students made observations about what they noticed about the flower stem and identified the differences in photos of two plants. They repeated this with a number of side-by-side photos. Tory labeled these different plants as "vascular" and "non-vascular" and summarized the differences that the students observed. The students looked at more photos and identified them as vascular or non-vascular and based their observations.

At the end of the class, Tory closed the lesson by asking students to, "Stop and think about how you've been a scientist today. Be specific." Liam responded, "We were using observations when we dissected things. We used tools when we dissected." Tory followed up with the question, "What was the purpose of us making those observations?" Walker said, "So we can see all of the parts of a flower instead of looking at a picture." Tory summarized, "We made observations so we could provide evidence for ourselves so that we could understand things better. How else?" Tyree responded, "When we were talking about vascular and non-vascular plants we used observations and made inferences about what kinds of plants they were." Tory said, "Isn't that what a scientist would do?" Several students responded, "Yes!" Tory asked, "Were we communicating with each other?" and Kiera said, "We shared observations and we made different observations." Tory said, "Absolutely, you have to socialize and talk to confirm information." James noted, "If scientists make an observation, not an observation but really an assumption and everyone could think they're right, they could have a total different story." Tory followed up with, "Which is why scientists have to back up their information with evidence." (Tory, Observation 3)

Other teachers employed discourse circles to support connected, student-centered NOS instruction at the end of a lesson. In these lessons, NOS ideas developed organically during student discussion. For example, in a 4th grade class after an activity in which students investigated electrical circuits with the goal of making a buzzer work, students first wrote what they learned from the investigation in their science notebooks. Then Abbie, their teacher, asked students to move into a discourse circle to discuss the activity and what they learned.

\section{Example 3}

In the discourse circle, Abbie said, "I would like in our discussion for us to include the vocabulary you used and also about the nature of science. Remember our rules that we let others talk if we've already spoken. Trice, go ahead and start us off." Trice summarized her findings and what her group needed to do to get the bulb to light up. Amanda clarified that the bulb did not light up all of the way. Abbie responded, "You think the amount of conductive clay changes the amount of light in the light bulb. We could experiment with that." Other students contributed their ideas. Nolan shifted the discussion to NOS saying, "we were like scientists because we worked together to try different things and we tried all of our ideas even if we thought it wasn't going to work." Abbie responded, "That is awesome. I like to hear that." (Abbie, Observation 3)

Like Tory and Abbie, teachers observed using connected, student-centered NOS instruction used questioning or discourse circles to promote student discussion of the NOS concepts within the lesson and to help students connect specific parts of activities to NOS 
concepts. Using discourse to explicitly debrief NOS was one strategy for incorporating NOS that was modelled during the PD that many teachers directly transferred in their own instruction.

In addition to connected, student-centered NOS instruction that occurred during the closure of lessons, some connected, student-centered NOS lessons were characterised by teachers' integrating NOS concepts into the body of a lesson. In these connected and student-centered lessons, teachers asked students to consider how the activities they were doing paralleled the work of scientists. In these instances, teachers embedded discussions of how they were being social or the use of observation and inference into body of a lesson immediately following when students made observations and inferences during the activity.

For example, as a part of their PBL unit, students in Cate's 4th grade class were tasked with creating a budget-friendly plan for increasing vegetation in their school courtyard. Prior to the observed lesson, students had discussed photosynthesis, phototropism, and began developing their plan by creating a preliminary map of the courtyard.

Example 4

Cate began by having students brainstorm what information they needed to find out. Students responded that they needed to learn about, "types of plans I might need," "what climate", "whether they should be in sun, shade, near water." Cate asked students if they knew what kind of conditions they would be in. Students responded that they have been making observations of where shade and sun are in the courtyard at different times of the day and the weather. Cate then pointed out that her class and the other class had both been taking data at different times during the day so the class actually has more data "as a group together than by yourselves." She asked the class to get out their science logs so they could share their data with each other. Cate then asked the students, "You guys are going to get together and share some of your data. What [nature of science] idea does that refer to?" Wes responded, "Science is a social activity." Cate said, "So sharing your data together is demonstrating that. What else?" Patience responded, "Ideas." Cate acknowledged this, "You guys are going to come up with some scientific ideas in your plan." Luis responded, "Logic and imagination." Cate then asked a student to explain how they're using logic and imagination and Jack said, "Using our imagination to come up with our plan for the courtyard." Cate followed up with, "What does logic mean?" Laura responded, "It has to be real, it can't be made up." After this brief discussion, Cate asked the students to continue with their plan. (Cate, Observation 1)

Examples two through four represented the most connected and student-centered of the explicit NOS instruction observed because students made the connections between the work of scientists and the activities they engaged in.

Missed opportunities. While many participants effectively integrated NOS concepts into their classroom science instruction, some lessons also potentially reinforced alternative conceptions about science and how scientists do their work. For example, in closure discussions about the 'social' nature of science, teachers indicated to students that they were 'being social like a scientist' because they were working in small groups; however, they did not push their students to extend this idea to the concept of how scientists share data or ideas or why collaboration is important to the development of scientific knowledge. In other cases, teachers used terms like 'proof and 'unbiased' when talking about the NOS concepts that scientific knowledge requires evidence. Generalising these two ideas may have inadvertently reinforced the alternative conception that scientific 
knowledge is absolute rather than revisionary. While these instances were not in majority, these missed opportunities may reflect a lack of understanding of these concepts, retention of absolutist perceptions of NOS, or an understanding how to transfer what they learned during the PD into their classroom instruction.

\section{Discussion and conclusion}

The results of the RCT reported here suggest that the PD, which was informed by situated learning theory and embedded NOS instruction within a PBL context, facilitated teachers' explicit NOS instruction. Significantly more treatment than control teachers integrated NOS concepts explicitly into instruction. More than half of these explicit NOS lessons were designed to teach the NOS concepts that scientific knowledge is empirically-based and that science is socially and culturally embedded. Variation in the extent to which explicit NOS instruction was connected with lesson activities/content, whether NOS reflection was teacher-driven or student-centered, and the temporal placement of teachers' incorporation of NOS concepts within a lesson existed. These results make several important contributions to the literature.

The few existing studies that explore teachers' NOS practices following PD used small samples of teachers (e.g. Akerson et al., 2009; Akerson \& Hanuscin, 2007; Bell et al., 2012; Herman et al., 2013; Mulvey et al., 2016) or relied on self-report regarding classroom practices implementation of explicit NOS instruction (e.g. Donnelly \& Argyle, 2011; Morrison et al., 2008). While such small-scale qualitative studies are useful for in-depth exploration of a phenomena, they do not allow for generalisation beyond the sample under investigation (Creswell, 2009). To our knowledge, no studies utilise classroom observations of a large sample of elementary teachers $(N=145)$ across a broad geographic region or an RCT with a mixed-methods design to ascertain explicit NOS instruction frequency, the NOS concepts incorporated, or how NOS concepts were implemented into classroom instruction. This research design allowed us to make statistical inferences about the degree to which elementary teachers' NOS instruction changed as a result of participation in the PD (i.e. the effect size) that previous small-scale studies have been unable to make.

\section{Frequency of NOS instruction}

Among our sample of 145 treatment teachers, 67\% were observed explicitly incorporated NOS concepts into their instruction at some point during the academic year following the summer institute compared to $2 \%$ of control teachers. Further, approximately half of the teachers that included explicit NOS instruction did so multiple times during the year. These classroom implementation results are encouraging given that prior to the PD, less than $2 \%$ of participants expressed aligned understandings of NOS and only one participant understood NOS needed to be taught explicitly (Maeng et al., 2016). These results support those of previous small-scale studies that also report explicit NOS implementation rates of approximately $70 \%$ for beginning secondary teachers following secondary teacher preparation programmes that featured intensive, sustained NOS instruction during the programme (e.g. Bell et al., 2012; Herman et al., 2013).

The results of the present study extend the findings of these prior studies in several important ways. First, we found similar NOS implementation rates for in-service 
elementary teachers' with mean teaching experience of 7 years. Research suggests that changing in-service teachers' practices, especially around explicit NOS instruction can be difficult (e.g. Johnson, 2006; Lederman \& Lederman, 2014), thus, this uptake in NOS implementation among elementary teachers is encouraging. Second, unlike the secondary science teachers in the Bell et al. (2012) and Herman et al. (2013) studies, all of whom were likely science majors (Herman et al., 2013 did not report this), only 12\% of the teachers in the present study were science majors. That $70 \%$ of teachers without substantial science content expertise were motivated to teach NOS concepts and were able to do so in primarily accurate ways following the 4-week summer institute, is remarkable, especially given that the PD the teachers attended consisted of substantially less contact time than a science teacher preparation programme.

\section{NOS concepts taught}

The elementary teachers in the present study most frequently included in their instruction the NOS concepts that science is empirically-based, socially and culturally-embedded, that science addresses questions about the natural world, and that creativity and imagination are important in science. Previous studies have shown teachers often incorporate the concepts that science is empirical, creative, and revisionary, or tentative (Akerson et al., 2009; Akerson \& Hanuscin, 2007; Bell et al., 2016). Further, teachers have been observed translating NOS concepts into 'kid-friendly language' when integrating them into instruction (Hanuscin, Lee, \& Akerson, 2010). Teachers in our study similarly used 'kid friendly' language to teach these NOS concepts.

Teachers in the present investigation frequently addressed the concept that science is a social endeavour and that science answers questions about the natural/material world, an aspect of NOS that teachers frequently overlook, even after PD. As exemplified by the discussions in Tory and Cate's classrooms, students discussed how they utilised each other's ideas, shared, data, and collaborated in groups to solve problems. It is possible the PBL framework, which heavily relies on data-sharing and collaboration, and within which teachers learned NOS, contributed to the inclusion of these NOS concepts to a greater extent than documented in previous investigations.

PBL supports students' working collaboratively to use science knowledge gained through investigations to creatively solve problems. Even so, it has not previously been utilised as an overarching context for teaching NOS concepts to teachers or students, although Moutinho et al. (2015) proposed it as a potential context for NOS instruction, based on the perceptions of preservice teachers as revealed by interviews. Consistent with these perceptions, we found that, following PD using a PBL context for NOS instruction, the observed lessons incorporated these NOS concepts, though with varying frequency. Overall, the positive outcomes of the present study support the efficacy of incorporating explicit NOS instruction within a PBL context as proposed by Moutinho et al. (2015).

\section{Characteristics of NOS instruction}

Several potential contexts for NOS instruction have been proposed in the literature. Though no empirical evidence exists to support a science content contextualised approach 
(e.g. science content, history of science, socio-scientific issues) as more effective than a non-contextualised approach (e.g. inquiry; see Bell et al., 2011; Khishfe \& Lederman, 2006), the NGSS emphasises a context of science content (NGSS Lead States, 2013). Clough (2006) argues for NOS instruction that uses both contextualised and non-contextualised instruction. Teachers in the present study were observed implementing connected explicit NOS lessons that used both contextualised and non-contextualised instruction to teach NOS concepts to their students.

Other studies have noted positive gains in student understanding of the role of evidence in the development of scientific knowledge and the social NOS through an explicit reflective approach (e.g. Akerson, Abd-El-Khalick \& Lederman, 2000; Khishfe \& Lederman, 2006). While we did not assess student outcomes related to NOS in the present study, we observed teachers promoting student-centered reflection of NOS concepts during and after activities. In particular, connected, student-centered NOS instruction in the present study was often characterised by the use of discourse circles to promote students' science talk. Research suggests that students' discourse about the nature of science has the potential to improve student learning and help them connect concepts (Roth, 2014). Taken together with the results of the present study, these findings suggest the NOS concepts that scientific knowledge is empirical and the role of creativity in science may be most facile for elementary teachers to implement using explicit-reflective approaches and for elementary students to understand.

\section{PD to support NOS}

Our research extends the work of Mulvey et al. (2016) who employed a situated learning approach to PD to support NOS understanding and instruction for special education elementary teachers to the general education elementary teacher population. Mulvey et al. (2016) observed similar outcomes to the present study in terms of the NOS concepts teachers implemented in their classroom instruction. The PD that served as the context of this investigation was unique in that it was tailored to the elementary science context, allowed for multiple opportunities for practice, feedback and reflection, and provided ongoing support within participants' classrooms and utilised PBL as the context for teaching NOS concepts. While teachers in the PD were introduced to all of the NOS concepts outlined in Figure 1, it appears that those NOS concepts that were revisited on multiple occasions during the PD were more often included in teachers' classroom instruction. Taken together, these findings provide further support for the efficacy of a situated approach to inform the design of PD to support elementary teachers' NOS instruction.

\section{Limitations and future research}

We are unable to tease out whether it was the PD as a whole or specific components of the $\mathrm{PD}$ that resulted in the changes in teacher practices. In addition, we do not know how the other components of the PD (e.g. ED instruction, inquiry instruction, technology integration) interacted with the NOS components of the PD to support teachers' NOS instruction. Future research should include interviews to disaggregate teacher perceptions of the components of the PD they perceive to be most influential in supporting their NOS instruction. In light of the positive results for elementary teachers found in the present 
RCT, the efficacy of PD aligned with situated learning theory that contextualises NOS instruction within PBL should be examined for in-service secondary teachers and preservice elementary and secondary teachers as well. Three categories emerged from our analysis of NOS instruction (connected/not connected, student-driven/teacher-driven, and temporal placement). These categories can inform future work that seeks to analyze NOS instruction. For example, the authors of the present investigation plan to conduct a second round of data analysis to calculate frequencies and further delineate the instructional strategies associated with each category for the 97 lessons that included NOS. Future research should also investigate student understandings of NOS when PBL is used as a context for explicit NOS instruction.

Despite the limitations of the present study, the positive changes in our elementary teachers' NOS frequency of explicit NOS instruction compared to teachers who did not participate in the PD are heartening. The results of the present investigation indicate situated PD contextualising NOS instruction within PBL is an effective approach for improving elementary teachers' explicit NOS instruction. Ultimately the results of the present study should be of interest to those developing PD that supports in-service elementary teachers' explicit classroom inclusion of NOS concepts.

\section{Disclosure statement}

No potential conflict of interest was reported by the authors.

\section{Funding}

This research was supported by funding from the U.S. Department of Education Investing in Innovation (I3) grant programme. However, the results presented here do not necessarily represent the policy of the U.S. Department of Education, and you should not assume endorsement by the Federal government.

\section{ORCID}

Jennifer L. Maeng (D) http://orcid.org/0000-0003-4955-4023

Tyler St. Clair (1) http://orcid.org/0000-0001-5297-9482

Brooke A. Whitworth (D) http://orcid.org/0000-0002-3944-291X

\section{References}

Abd-El-Khalick, F. S., \& Akerson, V. L. (2009). The influence of metacognitive training on preservice elementary teachers' conceptions of nature of science. International Journal of Science Education, 31, 2161-2184.

Abd-El-Khalick, F., Bell, R. L., \& Lederman, N. G. (1998). The nature of science and instructional practice: Making the unnatural natural. Science Education, 82, 417-436.

Akerson V. L., \& Abd-El-Khalick, F. (2003). Teaching elements of nature of science: A yearlong case study of a fourth-grade teacher. Journal of Research in Science Teaching, 40, 1025-1049.

Akerson, V. L., Abd-El-Khalick, F. S., \& Lederman, N. G. (2000). Influence of a reflective explicit activity-based approach on elementary teachers' conceptions of nature of science. Journal of Research in Science Teaching, 37, 295-317.

Akerson, V., Cullen, T. A., \& Hanson, D. L. (2009). Fostering a community of practice through a professional development program to improve elementary teachers' views of nature of science 
and teaching practice. Journal of Research in Science Teaching, 46, 1090-1113. doi:10.1002/tea. 20303

Akerson, V. L., Hanson, D. L., \& Cullen, T. A. (2007). The influence of guided inquiry and explicit instruction on K-6 teachers' views of nature of science. Journal of Science Teacher Education, 18, 751-772. doi:10.1007/s10972-007-9065-4

Akerson, V. L., \& Hanuscin, D. L. (2007). Teaching nature of science through inquiry: Results of a 3-year professional development program. Journal of Research in Science Teaching, 44, 653-680.

American Association for the Advancement of Science. (1993). Benchmarks for science literacy. New York: Oxford University Press.

Bell, R. L., Konold, T., Maeng, J. L., \& Heinecke, W. (2014). VISTA research and evaluation annual report. A report to George Mason University.

Bell, R. L., Matkins, J. J., \& Gansneder, B. M. (2011). Impacts of contextual and explicit instruction on preservice elementary teachers' understandings of the nature of science. Journal of Research in Science Teaching, 48, 414-436.

Bell, R. L., Mulvey, B., \& Maeng, J. L. (2012). Beyond understanding: Process skills as a context for nature of science instruction. In M. S. Khine (Ed.), Advances in the nature of science research: Concepts and methodologies (pp. 225-245). New York, NY: Springer.

Bell, R. L., Mulvey, B. K., \& Maeng, J. L. (2016). Outcomes of nature of science instruction along a context continuum: Preservice secondary science teachers' conceptions and instructional intentions. International Journal of Science Education, 38, 493-520. doi:10.1080/09500693.2016.1151960

Chin, C., \& Chia, L.-G. (2004). Problem-based learning: Using students' questions to drive knowledge construction. Science Education, 88, 707-727. doi:10.1002/sce.10144

Clough, M. P. (2006). Learners' responses to the demands of conceptual change: Considerations for effective nature of science instruction. Science \& Education, 15, 463-494.

Crawford, B. A. (2014). From inquiry to scientific practices in the science classroom. In N. G. Lederman, \& S. K. Abell (Eds.), Handbook of research on science education, volume II (pp. 593-613). New York, NY: Routledge.

Creswell, J. W. (2009). Research design: Qualitative, quantitative, and mixed methods approaches. Los Angeles: SAGE Publications.

Creswell, J. W., \& Plano Clark, V. L. (2011). Designing and conducting mixed methods research (2nd ed.). Thousand Oaks: SAGE Publications.

Desimone, L. M. (2009). Improving impact studies of teachers' professional development: Toward better conceptualizations and measures. Educational Researcher, 38, 181-199.

Donnelly, L. A., \& Argyle, S. (2011). Teachers' willingness to adopt nature of science activities following a physical science professional development. Journal of Science Teacher Education, 22, 475-490.

Driver, R., Leach, J., Millar, R., \& Scott, P. (1996). Young people's images of science. Buckingham: Open University Press.

Fan, X. (2001). Statistical significance and effect size in education research: Two sides of a coin. The Journal of Educational Research, 94(5), 275-282.

Gess-Newsome, J. (2002). The use and impact of explicit instruction about the nature of science and science inquiry in an elementary science methods course. Science \& Education, 11, 55-67. doi:10. 1023/A:1013054823482

Hanuscin, D. L., Lee, M. H., \& Akerson, V. L. (2010). Elementary teachers' pedagogical content knowledge for teaching the nature of science. Science Education, 95(1), 145-167. doi:10.1002/ sce. 20404

Herman, B. C., Clough, M. P., \& Olson, J. K. (2013). Teachers' nature of science implementation practices $2-5$ years after having completed an intensive science education program. Science Education, 97, 271-309.

Hmelo-Silver, C. E. (2004). Problem-based learning: What and how do students learn? Educational Psychology Review, 16, 235-266. doi:10.1023/B:EDPR.0000034022.16470.f3

Johnson, C. C. (2006). Effective professional development and change in practice: Barriers science teachers encounter and implications for reform. School Science and Mathematics, 106, 150-161. doi:10.1111/j.1949-8594.2006.tb18172.x 
Johnson, C. C., Kahle, J. B., \& Fargo, J. D. (2007). A study of the effect of sustained, whole-school professional development on student achievement in science. Journal of Research in Science Teaching, 44, 775-786. doi:10.1002/tea.20149

Kennedy, M. M. (2016). How does professional development improve teaching? Review of Educational Research, 86, 945-980. doi:10.3102/0034654315626800

Khishfe, R., \& Lederman, N. G. (2006). Teaching nature of science within a controversial topic: Integrated versus nonintegrated. Journal of Research in Science Teaching, 43, 395-418.

Lederman, N. G. (1999). Teachers' understanding of the nature of science and classroom practice: Factors that facilitate or impede the relationship. Journal of Research in Science Teaching, 36, 916-929.

Lederman, N. G. (2007). Nature of science: Past, present, and future. In S. K. Abell \& N. G. Lederman (Eds.), Handbook of research on science education, volume I (pp. 831-879). New York, NY: Routledge.

Lederman, N. G., \& Lederman, J. S. (2014). Research on teaching and learning of nature of science. In N. G. Lederman \& S. K. Abell (Eds.), Handbook of research on science education, volume II (pp. 600-620). NewYork, NY: Routledge.

Loucks-Horsley, S., Stiles, K. E., Mundry, S., Love, N., \& Hewson, P. (2010) Designing professional development for teachers of mathematics and science (3rd ed.). Thousand Oaks, CA: Corwin Press.

Maeng, J. L., Bell, R. L., St. Clair, T., Whitworth, B. A., \& Gonczi, A. L. (2016). From professional development to practice: Elementary teachers' understandings and enactment of nature of science instruction. A paper for the annual meeting of NARST, Baltimore, MD.

Mannarino, A., Logerwell, M. G., Reid, V. B., \& Edmondson, E. W. (2012). Refining inquiry-based science instruction through professional development using the VISTA model. A paper for the annual meeting of the national association of research in science teaching, Indianapolis, IN.

McComas, W. F., Clough, M. P., \& Almazroa, H. (1998). NOS in science education: An introduction. Science \& Education, 7, 511-532.

Miles, M. B., \& Huberman, A. M. (1994). Qualitative data analysis: An expanded sourcebook (2nd ed.). Thousand Oaks: Sage Publications.

Morrison, J. A., Raab, F., \& Ingram, D. (2008). Factors influencing elementary and secondary teachers' views on the nature of science. Journal of Research in Science Teaching, 46, 384-403.

Moutinho, S., Torres, J., Fernandes, I., \& Vasconcelos, C., (2015). Problem-based learning and nature of science: A study with science teachers. Procedia - Social and Behavioral Sciences, 191, 1871-1875.

Mulvey, B. K., Chiu, J. L., Ghosh, R., \& Bell, R. L. (2016) Special education teachers' nature of science instructional experiences. Journal of Research in Science Teaching, 53, 554-578.

NGSS Lead States. (2013). Next generation science standards: For states, by states. Washington, DC: National Academies Press.

Orgill, M. (2007). Situated cognition. In G. M. Bodner \& M. Orgill (Eds.), Theoretical frameworks for research in chemistry/science education (pp. 187-203). Upper Saddle River, NJ: Prentice Hall.

Osborne, J., Collins, S., Ratcliffe, M., Millar, R., \& Duschl, R. (2003). What "ideas-about-science" should be taught in school? A Delphi study of the expert community. Journal of Research in Science Teaching, 40, 692-720.

Roth, K. J. (2014). Elementary science teaching. In N. G. Lederman \& S. K. Abell (Eds.), Handbook of research on science education, volume II (pp. 600-620). NewYork, NY: Routledge.

Sadler, T., Burgin, S., McKinney, L., \& Ponjuan, L. (2010). Learning science through research apprenticeships: A critical review of the literature. Journal of Research in Science Teaching, 47, 235-256. doi:10.1002/tea.20326

Scharmann, L. C., Smith, M. U., James, M. C., \& Jensen, M. (2005). Explicit reflective nature of science instruction: Evolution, intelligent design, and umbrellaology. Journal of Science Teacher Education, 16, 27-41.

Schwartz, R. S., \& Lederman, N. G. (2002). It's the nature of the beast: The influence of knowledge and intentions on learning and teaching nature of science. Journal of Research in Science Teaching, 39, 205-236. doi:10.1002/tea.10021 
Schwartz, R. S., Lederman, N. G., \& Crawford, B. A. (2004). Developing views of NOS in anauthentic context: An explicit approach to bridging the gap between NOS and scientific inquiry. Science Teacher Education, 88, 610-645.

Supovitz, J. A., \& Turner, H. M. (2000). The effects of professional development on science teaching practices and classroom culture. Journal of Research in Science Teaching, 37, 963-980. doi:10. 1002/1098-2736(200011)37:9<963::AID-TEA6>3.0.CO;2-0 